\title{
Morpho-Physiological Response to Heat Stress During Seedling Stage and Interrelation With Agronomical Traits in Pepper (Capsicum Annuum L.) Cultivars Differing in Heat Tolerance
}

\section{Sherzod Rajametov ( $\nabla$ sherzod_2004@list.ru )}

National institute of horticultural and herbal science

\section{Eun Young Yang}

National institute of horticultural and herbal science

Myeong Cheoul Cho

National institute of horticultural and herbal science

\section{Soo Young Chae}

National institute of horticultural and herbal science

Hyo Bong Jeong

National institute of horticultural and herbal science

\section{Research Article}

Keywords: pepper, temperature, seedling, proline, chlorophyll, electrical conductivity, photosynthesis, fruit

Posted Date: December 10th, 2020

DOI: https://doi.org/10.21203/rs.3.rs-120894/v1

License: (c) (1) This work is licensed under a Creative Commons Attribution 4.0 International License.

Read Full License

Version of Record: A version of this preprint was published at Scientific Reports on July 12th, 2021. See the published version at https://doi.org/10.1038/s41598-021-93697-5. 


\section{Abstract}

Identification of heat tolerance trait in pepper genotypes is an important for the breeding of heat tolerant cultivars in pepper. Therefore, in the present study were investigated effect of heat treatment (HT) on morpho-physiological and biochemical status of two commercial pepper cultivars "Chyung Yang" and "New Bigarim" in seedling stage and their post-treatment reproductive ability. The seedlings with 8-10 true leaf stage were maintained at day and night temperature of $42^{\circ} \mathrm{C}$ for 10 days and cv. "Chyung Yang" were identified as a heat tolerant and "New Bigarim" as a susceptible to heat stress. The HT survival were revealed during 5 days and the threshold of heat tolerance were determined within 10 days of treatment among cultivars. We found no significant relation between leaf heat damage levels (LHD) with chlorophyll content $(\mathrm{CHL})$. During HT were identified significant reducing of the biomass of seedlings, whereas the photosynthetic rate $\left(P_{\mathrm{N}}\right)$, intercellular $\mathrm{CO}_{2}$ concentration $(C l)$, stomatal conductance $(G s)$ and transpiration rate $(T r)$ values were increased than in normal treatment (NT) seedlings. The cell membrane thermostability values were not steady during $\mathrm{HT}$ and in heat treated seedlings at recovery stages, where electrical conductivity $(\mathrm{EC})$ rate showed of the increasing in seedlings at HT than NT. Total free proline content (PRL) significantly increased in HT stressed seedlings over NT on day 5 of treatment, when survival of seedlings were finished. In both cultivar plants with different LHD were identified the significantly increasing of PRL than NT plants at recovery, where the mean fold increase within 2-3 times than in seedlings which were exposed to the HT. LHD significantly effected on reproductive growth stage, where LHD levels over $25 \%$ was critical for plants recovery. There no identified the any significant the linkage of heat tolerance in seedling stage with reproductive growth stage, where cv. "Chyung Yang" was determined as a heat tolerant in seedling stage but in reproductive stage it showed negative index of agronomical traits.

\section{Introduction}

The heat stress caused by elevated temperatures induces morphological, anatomical, physiological, biochemical and genetic responses in plants ${ }^{1-5}$. Photosynthetic and biochemical parameters are good indicators for detecting effects of stress on plants because photosynthesis and growth/yield are closely related [6-8]. Therefore, it is vital to elucidate mechanisms of plants in response to abiotic stress such as high temperatures, which may the reduction of reproductive success, destroy physiological activity and commonly translates into yield loss in agricultural setting ${ }^{2-5,9}$. Despite of this plants are able to protect themselves against an abiotic and biotic stresses, however the underlying mechanisms are not well understood yet ${ }^{5,10,11}$.

Pepper (Capsicum annuum L.) is an agriculturally important vegetable crops of global significance. The selection of heat-tolerant cultivars has become a key research topic of interest in pepper breeding under global climate changing conditions. The global warming exhibits potential impacts on agricultural production and food security throughout the world ${ }^{12-13}$. The increase in temperature above $30^{\circ} \mathrm{C}$ sianificantlv decreased the vield in pepper ${ }^{14}$. Therefore. fast screening methods were developed for Loading [MathJax]/jax/output/CommonHTML/fonts/TeX/fontdata.js 
identifying heat tolerant genotypes among crops of Solanaceae in different development stages ${ }^{5-6,8,15}$. However, tolerance of plant to high temperature regime is a developmentally regulated, stage specific phenomenon and tolerance at one stage of plant development can be related ${ }^{16}$ or no with tolerance at other developmental stages and the heat-threshold level varies for genotypes $2,12,17,18$.

Thus, present study was undertaken to understand the morpho-physiological and biochemical responses among two commercial pepper cultivars to heat stress in early seedling stage and find out the linkage of physiological traits with heat tolerance at reproductive development stage. While, there are very less information available on the influence of the degree of heat damages of pepper exposed to HT in seedlings stage on the agronomical traits at recovery that makes it difficult to assessment of heat tolerance potential of each genotype.

\section{Materials And Methods}

\section{Plant Materials and Growth Conditions}

Two commercial pepper cultivars "Chyung Yang" and "New Bigarim" seeds were sown in 31st March of 2020 in plastic trays containing $1: 1$ sand: peat by volume and grown in a glass greenhouse $\left(26 / 18{ }^{\circ} \mathrm{C}\right.$ $\mathrm{D} / \mathrm{N}$, with relative humidity within $65-70 \%$ ) in National institute of horticultural and herbal science, Jeonju, South Korea.

\section{Evaluation of heat tolerance of seedlings}

Plastic trays of pepper seedlings with 8-10 true leaf stage (40 days after sowing) were transferred on 11 May 2020 into growth chamber. The plants were maintained at day and night temperatures of $42{ }^{\circ} \mathrm{C}$, light intensity $600 \mu \mathrm{mol} \mathrm{m}-^{-2} \mathrm{~s}^{-1}(16 / 8 \mathrm{~h})$ and relative humidity was within $60-70 \%$. For each cultivars a total of 32 seedlings were treated. The pepper seedlings were maintained in heat treatment $(\mathrm{HT})$ for 10 days and all treated seedlings were well watered daily to avoid drought. All seedlings after treatments at high temperature were transferred into normal treatment condition $\left(\mathrm{D} / \mathrm{N} 26 / 18^{\circ} \mathrm{C}\right)$ and maintained for recovery 3 days.

Leaf heat damage levels (LHD) of pepper plants were identified according to method of Hong et al. ${ }^{19}$ with some modifications. The injured leaf part was calculated in \% and classified into 5 grades: grade 1, normal growth- no damage; grade 2 , fewer than $1 / 10$ damage of the leaves $(>10 \%)$ become lightly yellowed-whited or desiccated-dried; grade 3 , damages of the leaves from $11-25 \%$, become lightly yellowed-whited or desiccated-dried; grade 4 , damages $1 / 4$ to $1 / 2$ of the leaves (from 25 to $50 \%$ ) become lightly yellowed-whited or desiccated-dried; grade 5 , damage $1 / 2$ to $3 / 4$ of the leaves (from 50 to $75 \%$ ) become yellowed-whited or desiccated-dried; grade 6 , damage more than $3 / 4$ of the leaves $(>75 \%)$ become severely yellowed-whited or the whole plant dies.

\section{Measurement of total chlorophyll and photosynthesis in


Total chlorophyll content $(\mathrm{CHL})$ were measured using SPAD meter (Konica Minolta, Japan) in pepper leaves on 0 (NT), 1, 2, 5, 7 and 10 days of HT.

The photosynthetic rate- $P_{\mathrm{N}}\left(\mu \mathrm{mol} \mathrm{CO}_{2} \mathrm{~m}^{-2} \mathrm{~s}^{-1}\right)$, stomatal conductance - $\mathrm{Gs}\left(\mathrm{mol} \mathrm{H}_{2} \mathrm{O} \mathrm{m}^{-2} \mathrm{~s}^{-1}\right)$ intercellular $\mathrm{CO}_{2}$ concentration - $\mathrm{Ci}$, $\left(\mu \mathrm{mol} \mathrm{CO} \mathrm{Col}^{-1}\right)$, and transpiration rate $-\operatorname{Tr}\left(\mathrm{mmol} \mathrm{H}_{2} \mathrm{O} \mathrm{m-}{ }^{2} \mathrm{~s}^{-1}\right)$ were measured from 5-6th leaves of seedlings at NT ( 0 day) and on heat stress day 2 and day 7 between 10:00-12:00 am. Data were recorded in three plants per accessions using a portable photosynthesis measurement system (LI-6400, LI-COR Bioscience, Lincoln, NE, USA). Light response curves (PAR) was set to $800 \mu \mathrm{mol}$ $\mathrm{m}^{-2} \mathrm{~s}^{-1}$, the leaf chamber temperature was set to $25^{\circ} \mathrm{C}$, and the intercellular $\mathrm{CO}_{2}$ concentration was maintained at $400 \mu \mathrm{mol}\left(\mathrm{CO}_{2}\right)$ mol-1. The photosynthetic rate was measured automatically at each irradiation level after 3-4 min light exposure.

Determination of electrolyte leakage potential in leaves. The pepper leaves the $\mathrm{EC}$ was measured according to Hong et al. ${ }^{19}$ with minor modifications. In detail, leaves were perforated into discs with a radius of $5.5 \mathrm{~mm}$, and each disc was placed in a $15-\mathrm{mL}$ tube containing $10 \mathrm{~mL}$ of deionized water and incubated on a shaking table at $25^{\circ} \mathrm{C}$ for $30 \mathrm{~min}$. At this time, the conductivity $\left(\mathrm{EC}_{1}\right)$ of water was measured using a Thermo Orion STARA-HB conductivity meter (Thermo Orion., Waltham, MA, USA). The tube was heated in a boiling water bath for $30 \mathrm{~min}$, then cooled at room temperature for 20 minutes, and the conductivity $\left(\mathrm{EC}_{2}\right)$ was measured again. Final $\mathrm{EC}$ content was expressed as the percentage of $\mathrm{EC}_{1} / \mathrm{EC}_{2}$.

Extraction of free total proline content in leaves. Free total proline content (PRL) in pepper leaves was measured using colorimetric assay ${ }^{20}$. Leaf samples from heat treated plants and control were lyophilized $\left(-72^{\circ} \mathrm{C}\right)$ in Freezer dryer (IIShin BioBase, South Korea) for 3 days. Each leaf samples $100 \mathrm{mg}$ (dry weight) were homogenized with $2 \mathrm{ml}$ of $3 \%(\mathrm{w} / \mathrm{v}$ ) aqueous sulfosalicylic acid solution. The homogenate was centrifuge at $14,000 \mathrm{rpm}$ for 7 minutes. Then $1 \mathrm{ml}$ of supernatant was transferred to $5 \mathrm{ml}$ micro tubes and $1 \mathrm{ml}$ of acid ninhydrin (acid ninhydrin was prepared by adding ninhydrin $(2.5 \mathrm{~g} / 100 \mathrm{ml})$ to solution containing glacial acetic acid, distilled water and $6 \mathrm{M}$ ortho-phosphoric acid $85 \%$ at ratio of $6: 3: 1$ receptively) and $1 \mathrm{ml}$ of glacial acetic acid. Immediately the reaction mixtures were kept in boiling water bath $\left(95^{\circ} \mathrm{C}\right)$ for one hour. The reaction was stopped (boiled micro tubes were kept) at $4{ }^{\circ} \mathrm{C}$ for 20 minutes and reading were taken at wavelength of $546 \mathrm{~nm}$ by spectrophotometer (EON, BioTek Instruments, USA).

\section{Sampling of leaves for assaying EC and PRL.}

The leaves for EC and PRL measurements were selected from 5-6th leaves of seedlings at NT ( 0 day) and from HT with interval 1, 2, 5 and 7 days, and the leaves from mid part of plant on the 5th DAT at recovery.

\section{Determination of growth rate and biomass of heat treated seedlings}


Measurements of the growth parameters and biomass such as plant height, root length, fresh weight of plant and root were measured using ruler, electron Micro Weighing Scale MW-II (CAS), respectively after 10 days of HT.

Measurement of growth rate and reproductive parameters in plants with different leaf heat damage levels at recovery

After HT, to assay effects of LHD on agronomical traits the seedlings were transplanted into pots after 3 days of recovery and maintained in glass greenhouse condition (D/N $\left.30-32 / 22-24^{\circ} \mathrm{C}\right)$. The treatments were grouped according to LHD as control- normal treatment (NT), 25, 50 and 75\%. The soil in pots were prepared equally based on with pre-plant broadcast manure at a dose of $10,000 \mathrm{~kg} \mathrm{ha}^{-1}$ and basal fertilizer containing $160 \mathrm{~kg} \mathrm{ha}^{-1} \mathrm{~N}, 80 \mathrm{~kg} \mathrm{ha}^{-1} \mathrm{~K}_{2} \mathrm{O}, 160 \mathrm{~kg} \mathrm{ha}^{-1} \mathrm{P}_{2} \mathrm{O}_{5}$.

Measurement of growth rate (Plant height) of plants with different LHD were measured till 70 DAT into pots with interval 7 days during 4 weeks and then every 14 days.

Fruit set (FS, \%) was calculated as follows:

Fruit set $(\backslash \%)=\frac{\text { The number of fruits }}{\text { The number of flowers }} \times 100$

FS was determined by the sum of number of fruits (NF) in plant from first to fourth internodes of each plants. Fresh weight of total yield (TY) measured using electron Micro Weighing Scale MW-II (CAS), respectively.

\section{Statistical analysis}

The experimental design of this study was completely randomized. Statistical analysis (ANOVA) performed using the SAS Enterprise Guide 7.1 (SAS Institute Inc., NC, USA) for the data of the physiological and agronomical traits indexes, and mean values were compared with a significance level of $5 \%$ using Duncan's multiple range test. All sets of data were the means of three replicates.

\section{Results}

\section{Effect of heat treatment on seedlings}

Evaluation of high temperature tolerance of pepper seedlings showed that duration of seedlings survival to HT were 5 days for both cvs. "Chyung Yang" and "New Bigarim" in early juvenile stages, where the appearance of heat injury symptoms were observed. The symptoms of leaf heat damages slightly increased within 7 and 9th day of $\mathrm{HT}$, and on stress day 10 were identified the threshold of heat tolerance among seedlings, where cv. "New Bigarim" was detected as a significant heat susceptible. The index of tolerance in this cultivar were significantly reduced, where leaf heat injury symptoms were appeared as a 
wilted and desiccated with green-part leaf, and LHD increased to 67.4\%, whereas LHD in cv. "Chyung Yang" was within $47.6 \%$, respectively which identified as a relative heat tolerant in seedling phase.

\section{Effect of HT on total chlorophyll content}

At heat-stress condition the highest of $\mathrm{CHL}$ content among pepper seedlings were determined in heat susceptible cv. "New Bigarim" during 7 days of treatment than tolerant one cv. "Chyung Yang”. However, on heat stress day 10 were identified reduction in $\mathrm{CHL}$ content of cv. "New Bigarim" was observed. It should be noted that the seedlings of cv. "New Bigarim" displayed steady values of CHL within 2 days of HT, after it decreased.

\section{Effect of HT on photosynthesis}

In the present study, the HT significantly increased the $P_{\mathrm{N}}$ in both cultivars on the second day of treatment than NT, where the $P_{\mathrm{N}}$ rate was higher in heat tolerant cv. "Chyung Yang", but as mentioned above it was distinguished with low $\mathrm{CHL}$. However, $P_{\mathrm{N}}$ rate were decreased among seedlings on the 7 th day of HT (Fig. 1a), but there were observed a significant reduction in the $P_{\mathrm{N}}$ of cv. "Chyung Yang" on comparison with initial rate in NT, whereas in cv. "New Bigarim" the index of $P_{\mathrm{N}}$ were higher than in NT.

The stomatal conductance activity were significantly increased within 2 days of HT in both cultivars and the maximum index were detected within 7 days of treatment (Fig. 1b), where the highest significant Gs values were determined in susceptible of "New Bigarim".

After the application of high temperature treatment in both cultivars the intercellular COQ concentration were increased and index of $\mathrm{Ci}$ reached maximum on the 7th day of treatment, where no significant differences between cultivars were identified (Fig. 1c).

HT significantly increased the Tr in both cultivars within 2 days of treatment till the end of HT, but as mentioned above, the heat susceptible cv. "New Bigarim" distinguished with high values of Gs and Ci (Fig. 1d), and this pattern were also observed in the measurement of Tr than in heat tolerant cv. "Chyung Yang".

\section{Cell membrane thermo-stability in seedling leaves at HT and after short period recovery}

The mean values for EC among cultivars were displayed in Fig. 2. So, the highest EC index was detected in leaves of heat susceptible cv. "New Bigarim" and the smallest in tolerant cv. "Chyung Yang" at NT seedlings before HT, and almost the same pattern with no significant difference were observed among cultivars during 24 hours of the HT. However, on the 2nd and 5th day of HT the highest mean values for EC rate in cv. "Chyung Yang" seedlings than cv. "New Bigarim” were identified, and on the last seven days of $\mathrm{HT}$ the $\mathrm{EC}$ rate was significantly reduced in both cultivars.

The cell membrane thermostability in plants transplanted for short period recovery was ranged as Loading [MathJax]/jax/output/CommonHTML/fonts/TeX/fontdata.js ectrical leakage showed steady increasing 
among all cultivars with different LHD. In the heat tolerant cv. "Chyung Yang" the highest of EC rate was recorded on comparison with cv. "New Bigarim" at NT condition, whereas it showed the lowest leakage in seedling stage before HT. However, the plants with different LHD had the lowest of EC than NT, and the index of EC were highest with increasing of LHD in heat tolerant cv. "Chyung Yang". The same pattern were found in heat susceptible plants of cv. "New Bigarim".

\section{Proline content analysis in seedling leaves at HT and after short period recovery}

The highest PRL under NT condition was observed in cv. "Chyung Yang" at seedling stage and after transplantation of plants for recovery, while the lowest was recorded in heat susceptible cv. "New Bigarim" (Fig. 3). So, the seedlings which were subjected to heat stress treatment within 10 days showed different accumulation of PRL. Before subject of seedlings to HT the leaves of cv. "Chyung Yang" showed the highest concentration of PRL than cv. "New Bigarim" in NT condition, and the same values with small decreasing values were observed for 48 hours of HT. On the fifth day of HT were identified an increase in accumulation of PRL in heat sensitive seedlings of cv. "New Bigarim" than heat tolerant one cv. "Chyung Yang", and this tendency were observed till 7 days of treatment.

The measurement of PRL in plants after transplantation into pots for recovery showed that regardless of cultivars the heat treated plants with different LHD accumulated significantly high content of PRL than NT. The highest of PRL was observed in plants of cv. "New Bigarim" with LHD- $25 \%$ and $50 \%$, while in both cultivars plants with LHD- $75 \%$ were detected with no significant difference in values. The mean fold increase in PRL accumulation over NT was within 2.8 to 4.5 times in plants of cv. "Chyung Yang" with LHD from 25-75\%, and in cv. "New Bigarim" within 4.1 to 4.8 times, respectively on recovery day 5.

\section{Effect of heat treatment on morphological parameters and biomass of pepper seedlings}

The height of seedlings, values of fresh weight and roots reduced at $\mathrm{HT}$, where it revealed the negative effects of HT on seedlings in comparison with NT condition. The value differences were - 29.4, -29.5 and $-47.8 \%$, respectively for $\mathrm{cv}$. "Chyung Yang", and $-25.7,-45.2$ and $-19.6 \%$, respectively for $\mathrm{cv}$. "New Bigarim". The seedlings exposed to HT displayed the different response on the root growth rate, where the root length in cv. "Chyung Yang" seedlings were increased on 17.6\%, and opposite trend, the shortest of root length $-4.3 \%$ in comparison with NT seedlings were found in susceptible cv. "New Bigarim" (Fig. 4).

\section{Influence of different leaf heat damage levels on growth rate at recovery}

The plant growth rate in two cultivars subjected to HT decreased significantly in plants with LHD- 25 and $50 \%$ within 14 DAT than in NT plants, and in 21 DAT for LHD- 75\%, respectively at reproductive growth stages (Fig. 5). High intensity of growth rate differences were determined in all LHD plants within 6 weeks of transplantation than in NT. By comparison, the plant growth rate of both cultivars with different LHD 
was significantly higher in cv. "New Bigarim" than plants in NT, where all LHD plants reached NT plants rate on the 8th week of transplantation, and within the 10 weeks were observed outgrew of all LHD plants compared to NT (Figs. 6 and 7).

\section{Effect of different leaf heat damage levels on reproductive parameters}

Fruit set, as indicated by the percentage of seeded fruits produced upon mechanical self-pollination, was assessed in a commercial pepper cultivars under HT condition. Results showed that in comparison with NT plants there no identified any the significant differences of FS in cv. "Chyung Yang" with LHD- 25 and $50 \%$, while in plants with LHD- $75 \%$ was not determined the setting of the fruits from the first to fourth internodes (Table 1). However, in cv. "New Bigarim" the FS index were lower than NT plants. 
Table 1

Difference in reproductive parameters between NT and LHD plants of pepper cultivars after 70 days of transplanting

\begin{tabular}{|c|c|c|c|c|c|c|c|c|}
\hline $\begin{array}{l}\text { Leaf heat } \\
\text { damages }\end{array}$ & $\mathrm{PH}, \mathrm{cm}$ & $\begin{array}{l}\text { diff_PH, } \\
\%\end{array}$ & FS, \% & $\begin{array}{l}\text { diff_FS, } \\
\%\end{array}$ & NF & $\begin{array}{l}\text { diff_NF, } \\
\%\end{array}$ & $\begin{array}{l}\text { TY, } \\
\text { gram }\end{array}$ & $\begin{array}{l}\text { diff_TY, } \\
\%\end{array}$ \\
\hline \multicolumn{9}{|c|}{ cv. "Chyung Yang" } \\
\hline NT & $\begin{array}{l}191.7 \pm \\
6.0 a^{*}\end{array}$ & 0.0 & $\begin{array}{l}20.6 \pm \\
4.0 a^{\star}\end{array}$ & 0.0 & $\begin{array}{l}78.3 \pm \\
11.4 a^{*}\end{array}$ & 0.0 & $\begin{array}{l}303.8 \\
\pm 48.1 \\
a^{*}\end{array}$ & 0.0 \\
\hline LHD 25\% & $\begin{array}{l}193.7 \pm \\
5.8 \mathrm{a}\end{array}$ & 1.0 & $\begin{array}{l}20.6 \pm \\
6.3 a\end{array}$ & 0.0 & $\begin{array}{l}33.7 \pm \\
9.0 \mathrm{~b}\end{array}$ & -57.0 & $\begin{array}{l}140.0 \\
\pm 27.8 \\
b\end{array}$ & -53.9 \\
\hline LHD 50\% & $\begin{array}{l}182.3 \pm \\
8.2 \mathrm{a}\end{array}$ & -4.9 & $\begin{array}{l}24.8 \pm \\
18.1 \mathrm{a}\end{array}$ & 20.0 & $\begin{array}{l}19.8 \pm \\
5.1 \mathrm{~b}\end{array}$ & -74.8 & $\begin{array}{l}95.0 \pm \\
17.9 \mathrm{~b}\end{array}$ & -68.7 \\
\hline LHD 75\% & $\begin{array}{l}176.3 \pm \\
0.9 a\end{array}$ & -8.0 & 0.0 & -100.0 & $\begin{array}{l}9.7 \pm \\
5.8 \mathrm{~b}\end{array}$ & -87.6 & $\begin{array}{l}40.0 \pm \\
21.8 \mathrm{~b}\end{array}$ & -86.8 \\
\hline \multicolumn{9}{|c|}{ cv. "New Bigarim" } \\
\hline NT & $\begin{array}{l}128.7 \pm \\
4.2 \mathrm{a}\end{array}$ & 0.0 & $\begin{array}{l}69.0 \pm \\
7.7 \mathrm{a}\end{array}$ & 0.0 & $\begin{array}{l}37.8 \pm \\
2.8 \mathrm{a}\end{array}$ & 0.0 & $\begin{array}{l}561.3 \\
\pm 21.3 \\
a\end{array}$ & 0.0 \\
\hline LHD 25\% & $\begin{array}{l}146.7 \pm \\
10.1 \mathrm{a}\end{array}$ & 14.0 & $\begin{array}{l}55.6 \pm \\
24.2 \mathrm{a}\end{array}$ & -19.5 & $\begin{array}{l}28.7 \pm \\
9.9 \mathrm{a}\end{array}$ & -24.1 & $\begin{array}{l}328.3 \\
\pm 89.2 \\
\mathrm{~b}\end{array}$ & -41.5 \\
\hline LHD 50\% & $\begin{array}{l}140.0 \pm \\
9.1 \mathrm{a}\end{array}$ & 8.8 & $\begin{array}{l}65.2 \pm \\
10.6 \mathrm{a} .\end{array}$ & -5.5 & $\begin{array}{l}30.8 \pm \\
3.1 \mathrm{a}\end{array}$ & -18.5 & $\begin{array}{l}376.3 \\
\pm 41.8 \\
\mathrm{~b}\end{array}$ & -33.0 \\
\hline LHD 75\% & $\begin{array}{l}140.3 \pm \\
10.3 \mathrm{a}\end{array}$ & 9.1 & $\begin{array}{l}55.6 \pm \\
5.6 \mathrm{a}\end{array}$ & -19.5 & $\begin{array}{l}23.3 \pm \\
2.7 \mathrm{a}\end{array}$ & -38.4 & $\begin{array}{l}316.3 \\
\pm 40.5 \\
b\end{array}$ & -43.7 \\
\hline
\end{tabular}

The significant difference in the measurement of the number of fruits per plant between NT and LHD plants were determined in both cultivars, where it was reduced regardless of LHD. However, the plants of the cv. "New Bigarim" identified with more positive percent of differences than cv. "Chyung Yang", in which were revealed the highest negative percent.

Evaluation of the TY of both cultivars with different LHD showed that the plants subjected to HT and having over $25 \%$ of the LHD was critical for getting high yield per plant. The biggest negative differences in index of TY between NT and LHD plants were found in cv. "Chyung Yang". 


\section{Discussion}

Heat-tolerant cultivars are required to mitigate the adverse impact of changing climate without the reduced harvest exhibited by conventional, non-heat tolerant cultivars ${ }^{21}$. As expected, $\mathrm{HT}$ has significant effect on physiological and agronomical traits ${ }^{2,5,18}$, and duration of seedlings survival among cultivars can be ranged. Thus, duration of pepper seedlings survival was 5 days in both cultivars, but on the 7th day were revealed significant reduction of heat tolerance, and the threshold of heat tolerance for cv. "New Bigarim" was detected on the 10th day of HT, which was heat susceptible compared to the tolerant one cv. "Chyung Yang". This kind of the difference can be related with development stages, genotype features and structural changes of plant $11,16,22-23$.

We determined the physiological and biochemical status among pepper cultivars at $\mathrm{HT}$, while physiological parameters are fundamental for the understanding of plant responses to the environment, where an increase in maximum temperature above the thermal optimum should have a negative effect on physiological performance ${ }^{6,24-25}$.

The diurnal temperature and duration of heat treatment influence the physiological parameters of plants 16,24-25, that were found in our study, where values of $\mathrm{CHL}, \mathrm{EC}, \mathrm{PRL}, P_{\mathrm{N}}, \mathrm{Ci}, \mathrm{Gs}$ and $\operatorname{Tr}$ were ranged depends on the duration of treatment. So, at heat-stress condition, the $\mathrm{CHL}$ tends to decrease in leaves, whereas the magnitude of the change in heat-tolerant plants have to be smaller than in non-tolerant plants ${ }^{6,23,26-27}$, resulting in premature chlorosis ${ }^{28}$. While, greener leaves with low LHD under elevated temperatures contribute to better photosynthesis, which is an important agronomical characteristic of stay-green that contributes to higher yield under heat stress $^{29}$. However, in our case the CHL was higher in heat-susceptible cv. "New Bigarim" compared to the heat tolerant cv. "Chyung Yang" during HT, which indicate that the response of genotypes on stress is different ${ }^{24}$. And, we assume that the appearances of leaf heat injury symptoms are important in comprehensive evaluation of heat tolerance, whereas in heat tolerant seedlings cv. "Chyung Yang" were observed yellowing of leaf parts but in heat-susceptible cv. "New Bigarim" were determined wilting and desiccating without yellowing- degradation of $\mathrm{CHL}$, resulting in premature drying. While, it is known that chlorophyll fluorescence induction method such as Fv/Fm can often correlate with the state of photosynthetic apparatus ${ }^{30,31}$.

Our results are not in accordance with previous reports ${ }^{6,16,23}$, where indicated that the photosynthetic apparatus in heat-tolerant cultivar with high $\mathrm{CHL}$ have better stability than that of the heat-susceptible. Since, in our present study the HT significantly increased the $P_{\mathrm{N}}$ in both cultivars compared to the NT seedlings, where heat tolerant cv. "Chyung Yang" showed low CHL. Also, in our previous work we identified high concentration of $\mathrm{CHL}$ in tomato leaves, even though $P_{\mathrm{N}}$ values were significantly reduced in low temperature condition ${ }^{32}$, and this kind of differences can be explained by the fact that the response of the genotype differing in heat stress condition. 
While, $G s$ is regulated to accommodate the need for $\operatorname{Cifor} P_{\mathrm{N}}$. As a consequence of being able to maintain high rates of $P_{N}$, the higher $G s$ and $T r$ during heat stress improved leaf cooling in the heattolerant genotypes for protection, if temperatures are close to the threshold for heat damage ${ }^{6}$. However, our results contradict some conclusions, where the high rate of $P_{\mathrm{N}}$ was detected in heat tolerant $\mathrm{cv}$. "Chyung Yang" on stress day 2 but on day 7 it reduced significantly, whereas cv. "New Bigarim" maintained high rate of $P_{\mathrm{N}}$ than initial rate at NT yet. It can be explained that in heat susceptible plants protection mechanisms still were more activated than tolerant one to avoid the death of plants from heat stress and decrease in $P_{\mathrm{N}}$ values was the result of non-stomatal factors ${ }^{2,8,16}$.

Heat treatment made to significantly increase the Trin heat susceptible ${ }^{25} \mathrm{cv}$. "New Bigarim" seedlings on stress day 2 and day 7, and this pattern were also revealed in measurement of Gs than in heat tolerant cv. "Chyung Yang". If air temperature is very high and the plant's regulatory mechanism could not maintain the leaf temperature at its thermal optimum ${ }^{25}$, then a decrease in $\mathrm{Ci}$, maximum $P_{\mathrm{N}}$ and $G s$ would be caused by an increase in stomatal limitation, but in our results were identified increasing of trends of $G s$, $\mathrm{Ci}$ and $\mathrm{Tr}^{32}$. There no identified significant interrelation between the increasing of $G s$ and $T r$ with heat tolerance that allows the better cooling of the leaf with limits $P_{\mathrm{N}}$ in the sensitive cv. "New Bigarim" plants at $\mathrm{HT}^{6}$. Since, $\mathrm{Ci}$ was slightly increased with no significant difference at $\mathrm{HT}$ among cultivars and unaffected.

In line with this, heat tolerant cultivar had more stable ${ }^{2}$ or higher membranes ${ }^{22}$ in comparison with a heatsusceptible one, and cell membrane thermo-stability has often been linked to $P_{\mathrm{N}}$ and $\operatorname{Tr}$ at $\mathrm{HT}^{12}$, however these latter two traits do not seem to be affected much by moderate heat-stress ${ }^{1,33}$, while in our results we did not find any significant relation between membrane stability and reproductive traits.

The plants response mechanism to environmental stress is the accumulation of osmoprotector solutes, such as PRL ${ }^{20,34}$ and generally found in large amounts under any stress conditions ${ }^{15,22,35}$. In the present study regardless of cultivars, high accumulation of the PRL in all LHD plants on recovery day 5 was observed, where the mean fold increased significantly over NT plants. It indicates that the plants were under stress condition and protection mechanisms were activated yet. These tendency indicated that pepper plants subjected to high temperature in seedling stage experienced high stress levels by recovery, as accumulation of PRL is considered a strong indicator of abiotic stress ${ }^{15,35}$, and we agreed with conclusion of some researchers ${ }^{36,37}$ that high accumulation of PRL in plants during $\mathrm{HT}$ is detrimental for plant growth at recovery, which is not always a compatible solute during environmental stresses and high doses will impart toxic effects and may significantly delay the growth rate of plant. Thus, PRL surplus is probably channeled and used in other metabolic pathways instead of producing of specific hormones or may hinders the growth activates.

Evaluation of effect HT on vegetative parameters of seedlings showed that regardless of cultivar fresh weight of seedlings and roots were decreased than NT seedlings, where we could not find any significant Loading [MathJax]/jax/output/CommonHTML/fonts/TeX/fontdata.js

Page $11 / 21$ 
difference of biomass between heat tolerant and sensitive cultivar. While, a decrease in $P_{\mathrm{N}}$ rate during HT, was reflected in seedling growth parameters, where photosynthesis deficit may disrupt the metabolic pathways and reduce the growth rate and biomass, whereas the tolerant genotypes accumulated more biomass, with lower heat injury index and higher fruit yield ${ }^{6,38}$.

In the plants of pepper with different LHD significantly reduced both FS and NFR per plant regardless of cultivars. The fruit setting is the main indicator for screening the response of genotype on abiotic stress

condition $^{1,5,32}$, and heat stress may significantly reduce or increase the FS and number of flowers $5,17,18,22$.

We observed in the current study that the plants which were subjected to HT in seedling stage and had a different LHD may a FS to a large extent, on par with NT plants regardless of cultivars. However, the NFR per plant was drastically reduced.

NFR can be used as predictor for FS in screening of the heat tolerant genotype since it positively correlates with FS in $\mathrm{HT}$ and that $\mathrm{NT}^{16,18}$. The plants of the cv. "New Bigarim" with different LHD identified with more positive percent of differences in FS and NFR, which were screened as heat susceptible in seedling stage than cv. "Chyung Yang". We agreed with the hypothesis that genotypes with good FS under NT can be pre-selected simply for screening on heat tolerance ${ }^{5,16,18}$.

The different LHD caused a decrease in TY of both pepper cultivars, where over $25 \%$ of the LHD was critical for producing economic harvest per plant. And, as mentioned above the cv. "Chyung Yang" distinguished as a heat tolerant in seedling stage showed the biggest negative differences in index of yield between NT and LHD plants. There are no identified positive relation between PRL and reproductive parts ${ }^{39}$, whereas heat tolerant genotype have to accumulate high PRL and produces the higher fruit yields ${ }^{22}$, and we could not find any the linkage between the seedlings and reproductive growth stages in heat tolerance, which confirmed in other results ${ }^{5}$.

\section{Conclusion}

Based on this investigation we identified that heat tolerant genotypes in early seedling stage may not be tolerant in reproductive stage, it is a complex manner. The duration of the survival of plants to HT and the threshold value for tolerance were determined on stress day 5 and day 10 , respectively. Measurement of the total chlorophyll content by SPAD meter cannot be used as the main indicator for screening heat tolerant genotype in early juvenile stage, while chlorophyll a fluorescence is a highly sensitive induction method to assay the abiotic stress responses of the plant. However, response of the heat tolerance are related with each individual genotype's features on survival and duration of the treatment. Heat stress may contribute to increase the $P_{\mathrm{N}}, \mathrm{Ci}, \mathrm{Gs}$ and $\operatorname{Tr}$ values and root length than in NT seedlings, however it reduced significantly the biomass of vegetative parts of plant. The cell membrane thermostability and PRL values were not steady at the seedling stage and ranged among cultivars depends on duration of HT, however the PRL content significantly increased in all LHD plants than in NT and those may be used as 
where LHD levels over $25 \%$ was critical for plants. We assume that physiological traits associated with $\mathrm{HT}$ tolerance differ by genotype and growth stages, and breeding programs should be consider different selection criteria for screening heat tolerant genotype.

\section{Declarations}

\section{AUTHOR CONTRIBUTION STATEMENT}

Yang, Cho and Rajametov designed experiments; Rajametov, Chae, Jeong performed experiments; Rajametov, Yang and Cho wrote the manuscript.

\section{ACKNOWLEDGMENTS}

This study was supported by a grant (Project No: PJ01267102 "Study on the physiological mechanism of temperature adaptable pepper lines") from National Institute of Horticultural and Herbal Science, Rural Development Administration.

\section{COMPLIANCE WITH ETHICAL STANDARDS}

This article does not contain any studies involving animals or human participants as objects of research. The authors declare that they have no conflict of interest.

\section{DATA AVAILABILITY}

The datasets generated during and/or analyzed during the current study are available from the corresponding author on responsible request.

\section{References}

1. Sato, S., Peet, M.M., and Thomas, J.F. Physiological factors limit fruit set of tomato (Lycopersicon esculentum) under chronic, mild heat stress. Plant. Cell Environ. 23, 719-726 (2000). https://doi:10.1046/j.1365-3040.2000.00589.x

2. Camejo, D., Rodriguez, P., Morales, M.A., Dell'Amico, J.M., Torrecillas, A., and Alarcon, J.J. High temperature effects on photosynthetic activity of two tomato cultivars with different heat susceptibility, Plant Physiol. 162, 281-289. (2005). https://doi.org/10.1016/j.jplph.2004.07.014.

3. Song, Y., Chen, Q., Ci, D., Shao, X., and Zhang, D. Effects of high temperature on photosynthesis and related gene expression in poplar. BMC Plant Biol. 14, 111. (2014). https://doi.org/10.1186/14712229-14-111.

4. Munir, S., Liu, H., Xing, Y., Hussain, S., Ouyang, B., Zhang, Y., Li, H., and Ye, Zh. Overexpression of calmodulinlike (ShCML44) stress-responsive gene from Solanum habrochaites enhances tolerance to multiple abiotic stresses. Rep. 6, 31772 (2016). http://doi.org/10.1038/srep31772 
5. Xu, J., Wolters-Arts, M., Mariani, C., Huber, H., and Rieu, I. Heat stress affects vegetative and reproductive performance and trait correlations in tomato (Solanum lycopersicum). 213, 156. (2017). https://doi:10.1007/s10681-017-1949-9

6. Poudyal, D., Rosenqvist, E., and Ottosen, C.O. Phenotyping from lab to field - tomato lines screened for heat stress using Fv/Fm maintain high fruit yield during thermal stress in the field. Functional Plant Biology. 46(1). https://doi.org/10.1071/FP17317 (2018)

7. Rivero, R.M., Mestre, T.C., Mittler, R., Rubio, F., Garcia-Sanchez, F., Martinez, V. The combined effect of salinity and heat reveals a specific physiological, biochemical and molecular response in tomato plants. Plant Cell Environ. 37, 1059-1073 (2014). http://doi.org/10.1111/pce.12199

8. Zhou, R., Wu, Z., Wang, X., Rosenqvist E., Wang, Y., Zhao, T., and Ottosen, C.O. Evaluation of temperature stress tolerance in cultivated and wild tomatoes using photosynthesis and chlorophyll fluorescence. Environ. Biotechnol. 59, 499. (2018). https://doi.org/10.1007/s13580-018-0050-y

9. Asseng, S., Foster, I., Turner, N.C. The impact of temperature variability on wheat yields. Glob Change Biol. 17, 997-1012 (2011). doi:10.1111/j.1365-2486.2010.02262.x

10. Zinn, K.E., Tunc-Ozdemir, M., Harper, J.F. Temperature stress and plant sexual reproduction: uncovering the weakest links. Exp. Bot. 61, 1959-1968 (2010). doi:10.1093/jxb/erq053

11. Rieu, I., Twel,I D., Firon, N. Pollen development at high temperature: from acclimation to collapse. Plant Physiol. 173, 1967-1976 (2017). https://doi:10.1104/pp.16.01644

12. Wahid, A., Gelani, S., Ashraf, M., and Foolad, M.R. Heat tolerance in plants: An overview. Expt. Bot. 61, 199-223. (2007). https://doi:10.1016/j.envexpbot.2007.05.011

13. Wang, H.J., Rutishauser, T., Tao, Z.X., Zhong, S.Y., Ge, Q.S., and Dai, J.H. Impacts of global warming on phenology of spring leaf unfolding remain stable in the long run. J. Biometeorol. 61, 287-292. (2017). https://doi:10.1007/s00484-016-1210-3

14. Berke, T., Black, L.L., Talekar, N.S., Wang, J.F., Gniffke, P., Green, S.K., Wang, T.C., and Morris, R. Suggested cultural practices for Chilli pepper. International Co-Operator's Guide. 2005.

15. Bhandari, S.R., Kim, Y.H., and Lee, J.G., Detection of temperature stress using chlorophyll fluorescence parameters and stress-related chlorophyll and proline content in paprika (Capsicum annuum) seedlings. Korean J. Hortic. Sci. Technol. 36(5), 619 (2018). https://doi.org/10.12972/kjhst.20180062

16. Zhou, R., Kjaer, K.H., Rosenqvist, E., Yu, X., Wu, Z., and Ottosen, C.O. Physiological response to heat stress during seedling and anthesis stage in tomato genotypes differing in heat tolerance. Crop. Sci., 203, 68-80. (2017). https://doi.org/10.1111/jac.12166

17. Kaur, N., Dhaliwal, M.S., Jindal, S., and Singh, S. Evaluation of Hot Pepper (Capsicum annuum) Genotypes for Heat Tolerance during Reproductive Phase. Intl. J. Bio-resour. Stress Manage. 7(1), 126. (2016). https://doi:10.5958/0976-4038.2016.00020.8

18. Rajametov, Sh., Yang, E.Y., Cho, M.Ch., Chae, S.Y., and Won, B.Ch. Physiological traits associated with high temperature tolerance differ by fruit types and sizes in tomato (Solanum lycopersicum). Hortic. 
19. Hong, B., Ma, C.Y., Yang, T., Wang, K., Yamaguchi-Shinozaki, and J. Gao. Over-expression of AtDREB1A in Chrysanthemum enhances tolerance to heat stress. Plant Mol. Biol. 70, 231-240 (2009). https://doi.org/10.1007/s11103-009-9468-z

20. Claussen, W. Proline as a measure of stress in tomato plants. Plant Science. 168, 241-248 (2005). https://doi.org/10.1016/j.plantsci.2004.07.039

21. Solankey, S.S., Singh R.K., Baranwal D.K. \& Singh D.K. Genetic expression of tomato for heat and drought stress tolerance: An Overview. Intl J. Veg. Sci. 21(5), 496-515 (2015). https://doi.org/10.1080/19315260.2014.902414

22. Din, J.U., Khan, S.U., Khan, A., Qayyum, A., Abbasi, K.S., and Jenks, M.A. Evaluation of potential morpho-physiological and biochemical indicators in selecting heat-tolerant tomato (Solanum lycopersicum) genotypes. Hortic. Environ. Biotechnol. 56(6), 769-776 (2015).

https://doi:10.1007/s13580-015-0098-x

23. Chen, W., Zhu, X., Han, W., Wu, Zh., and Lai, Q. Morphological, physiological and biochemical responses of Gerbera cultivars to heat stress, Korean J. Hortic. Sci. Technol. 34(1), 1 (2016). http://dx.doi.org/10.12972/kjhst.20160018

24. Rajametov, Sh., Yang, E.Y., Chae, S.Y., Chae, W.B., Nam, Ch.W., and Cho, M.Ch. Evaluation of photosynthetic, chlorophyll and leaf temperatures parameters in pepper lines under high temperature condition. Abstracts of conference on '2019 Annual Spring Conference of the Korean Society for Horticultural Science. Korean J. Hortic. Sci. Technol. 37 Suppl I., May, 210. (2019). http://www.dbpia.co.kr/journal/articleDetail?nodeld=NODE08740426

25. Garruna-Hernandez, R., Orellana, R., Larque-Saaverda, A., and Canto, A. Understanding the physiological responses of a tropical crop (Capsicum Chinense) at high temperature. PLoS One. 3, 9 (2014). https://doi:10.1371/journal.phone.0111402

26. Wang, J.Z., Cui, L.J., Wang, Y., and Li, J.L., Growth, lipid peroxidation and photosynthesis in two tall fescue cultivars differing in heat tolerance. Plant. 53, 237 (2009). https://doi.org/10.1007/s10535009-0045-8

27. Lu, T., Meng, Z., Zhang, G., Qi, M., Sun, Z., Liu, Y. and Li, T., Sub-high Temperature and High Light Intensity Induced Irreversible Inhibition on Photosynthesis System of Tomato Plant (Solanum lycopersicum). Front. Plant Sci. 8, 365 (2017). https://doi.org/10.3389/fpls.2017.00365

28. Zhou, R., Yu, X., Kjær, K.H., Rosenqvist, E., Ottosen, C-O., Wu, Z. (Screening and validation of tomato genotypes under heat stress using Phenotyping tomato for heat tolerance Functional Plant Biology $\mathrm{K}$ $\mathrm{Fv} / \mathrm{Fm}$ to reveal the physiological mechanism of heat tolerance. Exp. Bot. 118, 1-11 (2015). doi:10.1016/j.envexpbot.2015.05.006

29. Sharma, D.K, Andersen, S.B., Ottosen, C-O., Rosenqvist, E. Wheat cultivars selected for high Fv/Fm under heat stress maintain high photosynthesis, total chlorophyll, stomatal conductance, transpiration and dry matter. Physiologia Plantarum. 153, 284-298 (2015). doi:10.1111/ppl.12245

30. Kalaji, H.M., Schansker, G., Ladle, R.J., et al. Frequently asked questions about in vivo chlorophyll 
014-0024-6

31. Stirbet, A., Govindjee. On the relation between the Kautsky effect (chlorophyll a fluorescence induction) and Photosystem II: basics and applications of the OJIP fluorescence transient. J. Photochem. Photobiol. B. Biol: 104, 236-257 (2011). http://doi.org/10.1016/j.jphotobiol.2010.12.010

32. Rajametov, Sh., Yang, E.Y., Cho, M.Ch., Chae, S.Y., Kim, J.H., Nam, Ch.W., and Won, B.Ch. Traits Affecting Low Temperature Tolerance in Tomato and its Application to Breeding Program. Plant Breed. Biotech. 7(4), 350-359 (2019). https://doi.org/10.9787/PBB.2019.7.4.350

33. Jiang, J., Liu, X., Liu, G., Li, S., and Wang, L. Intergrating omics and alternative splicing reveals insights into grape response to high temperature. Plant Physiol. 173, 1502 (2017). https://doi:10.1104/pp.16.01305

34. Rivero, R.M., Ruiz, J.M., and Romero, L., Importance of $\mathrm{N}$ source on heat stress tolerance due to the accumulation of proline and quaternary ammonium compounds in tomato plants. Plant Biology. $\mathbf{6}$, 702. (2004). https://doi:10.1055/s-2004-821293

35. Ruiz, J.M., Sanchez, E., Garcia, P.C., Lopez-Lefebre, L.R., Rivero, R.M., and Romero, L. Proline metabolism and NAD kinase activity in greenbean plants subjected to cold-shock. 59, 473. (2002). https://doi.org/10.1016/S0031-9422(01)00481-2

36. Lv, W.T., Lin, B., Zhang, M., and Hua, X.J. Proline accumulation Is Inhibitory to Arabidopsis Seedlings during Heat Stress. Plant Physiology. 156, 1921 (2011). https://doi.org/10.1104/pp.111.175810

37. Hayat, Sh., Hayat, Q., Alyemeni, M., Wani, A., Pichtel, J., and Ahmad, A., Role of proline under changing environments- A review. Plant Signaling \& Behavior. 7 (11), 1456 (2012). http://dx.doi.org/10.4161/psb.21949

38. Zhou R., Kong L., Wu Z., Rosenqvist E., Wang Y., Zhao L., Zhao T., and Ottosen C. Physiological response of tomatoes at drought, heat and their combination followed by recovery. Physiologia Plantarum. 165:144-154 (2019). doi:10.1111/ppl.12764

39. Kumararathna, P., Cho, M.Ch., Rajametov, Sh., Kim, J.H., Chae, S.Y., Nam, Ch.W., Yang, E.Y., and Chae, W.B., Application of proline content and electrical conductivity to selection methods for high temperature tolerance in tomato (Solanum lycopersicum). Abstracts of conference on '2019 Annual Autumn Conference of the Korean Society for Horticultural Science. Kor. J. Hortic. Sci. Technol. 37 Suppl. II. October 2019, 107 (2019). http://www.dbpia.co.kr/journal/articleDetail? nodeld=NODE09263592

\section{Figures}



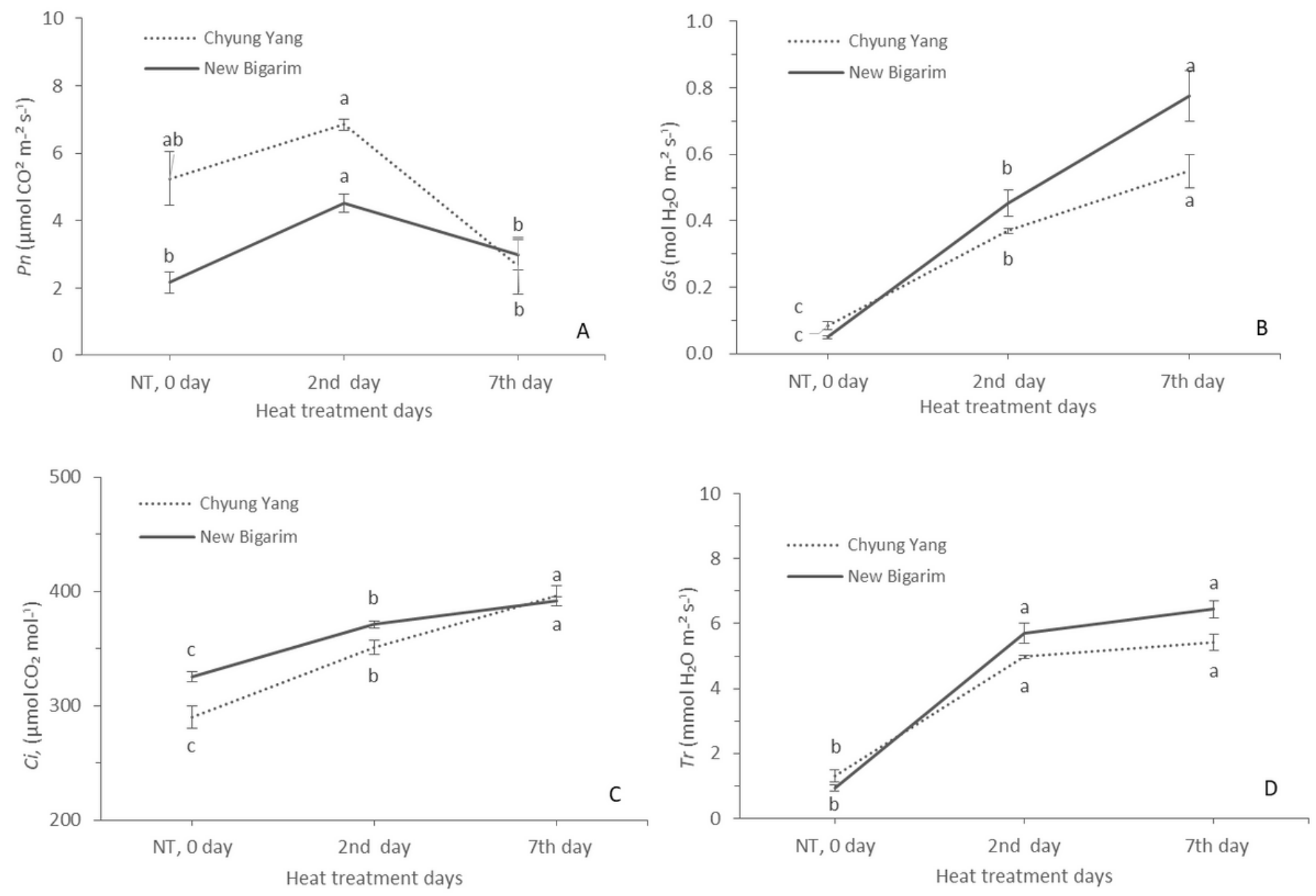

Figure 1

Photosynthetic activity (A), Stomatal conductivity (B), Intercellular CO囚 concentration (C), Transpiration rate (D). Vertical bars represent standard error $(n=3)$. Different letters in the same column indicate significant difference based on Duncan's multiple range test $(p<0.05)$. 


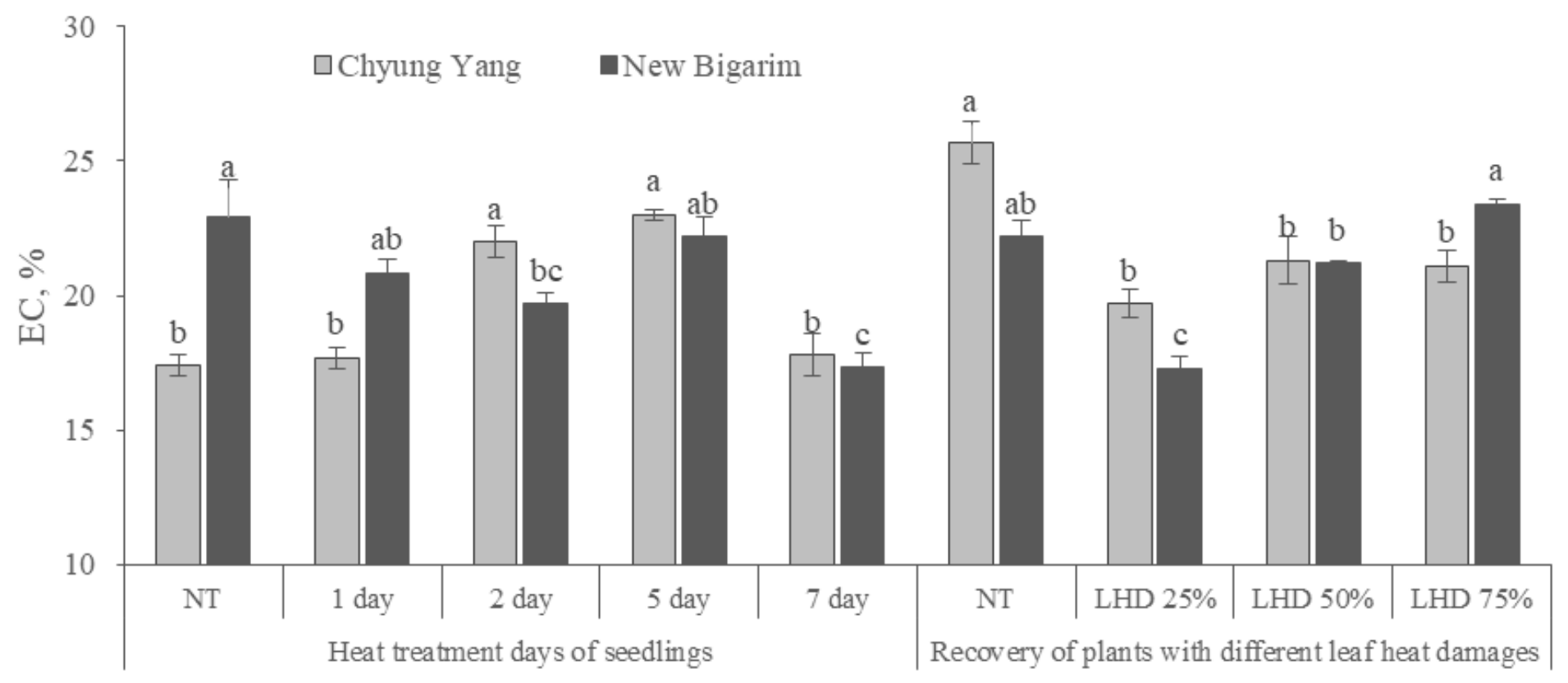

\section{Figure 2}

Electrical conductivity in seedlings at HT and recovery stage of pepper cultivars. Values are means $(n=3)$ \pm SE. Within each parameter, histograms with same letter indicate that values are similar $(p<0.05)$.

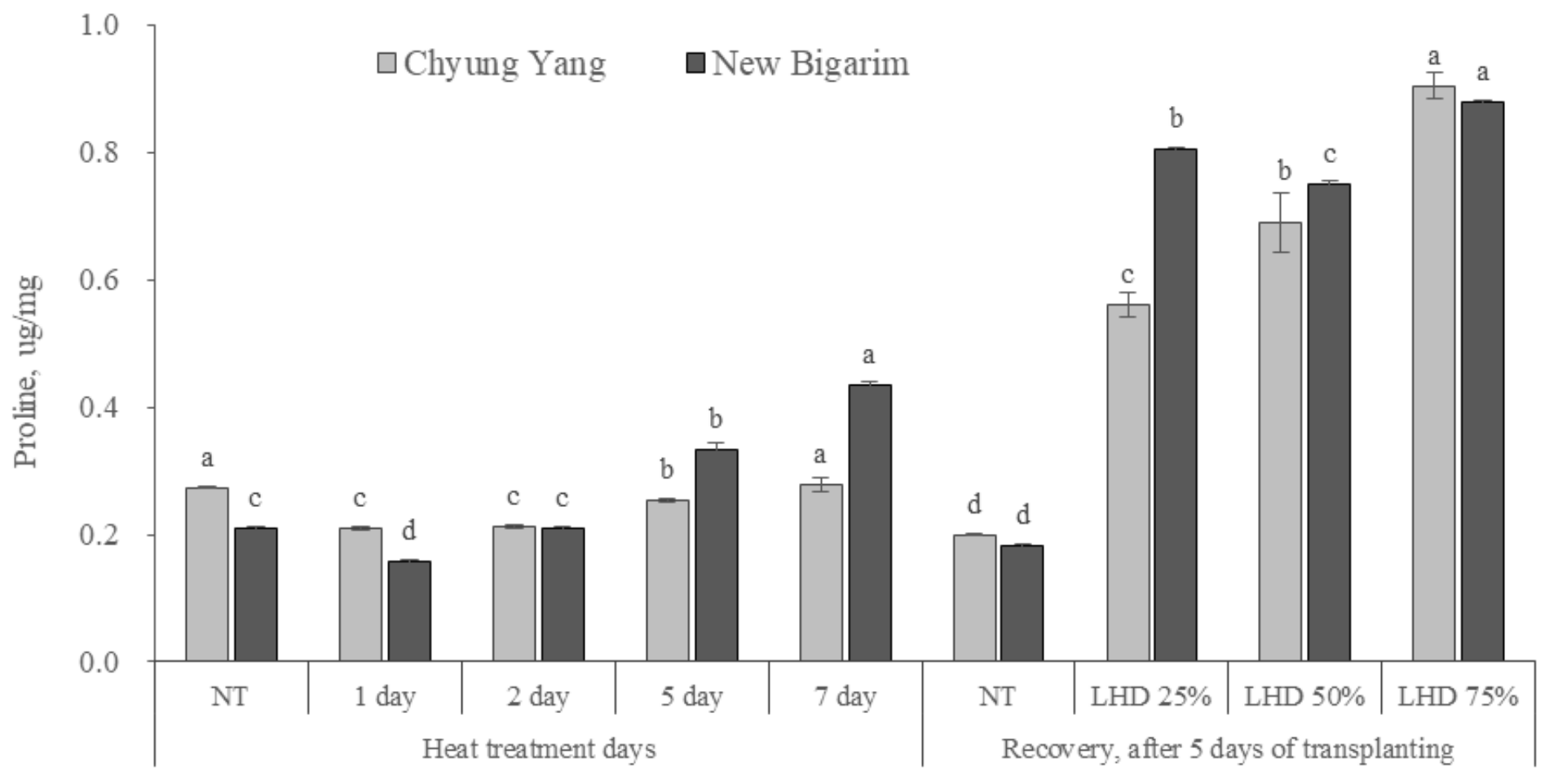

\section{Figure 3}

Changing of proline content in seedlings at heat treatment and recovery stage of pepper cultivars. Vertical bars represent standard error $(n=3)$. Within each parameter, histograms with same letter indicate that 


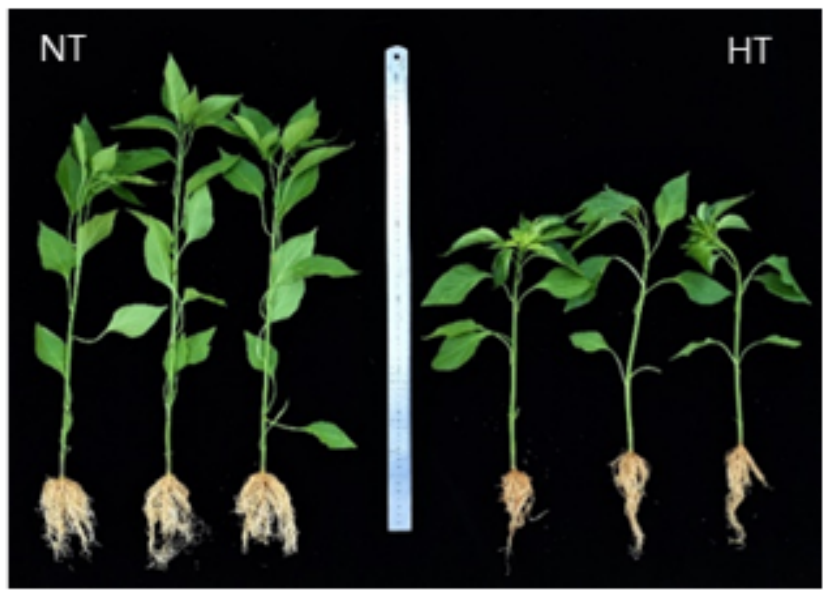

cv. "Chyung Yang"

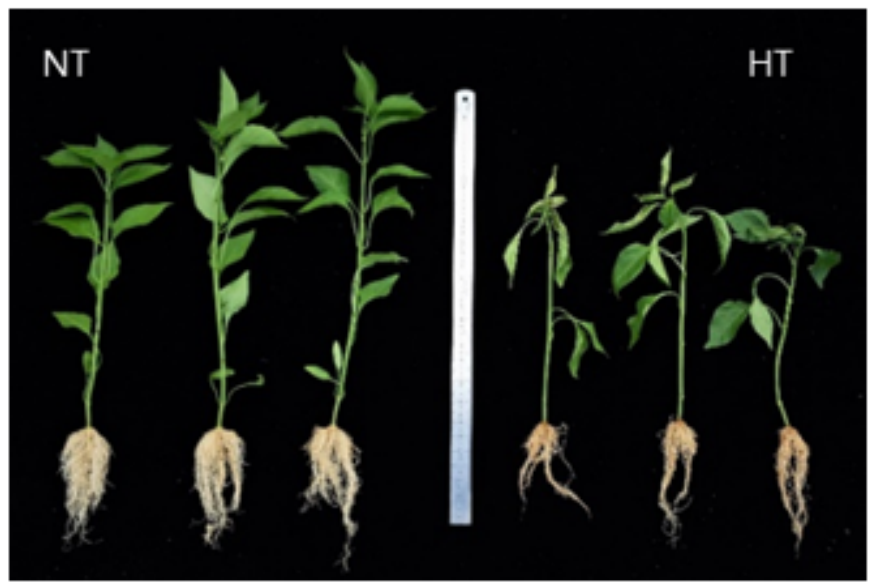

cv. "New Bigarim"

Figure 4

Effect of heat treatment on vegetative parameters among seedlings of pepper cultivars.

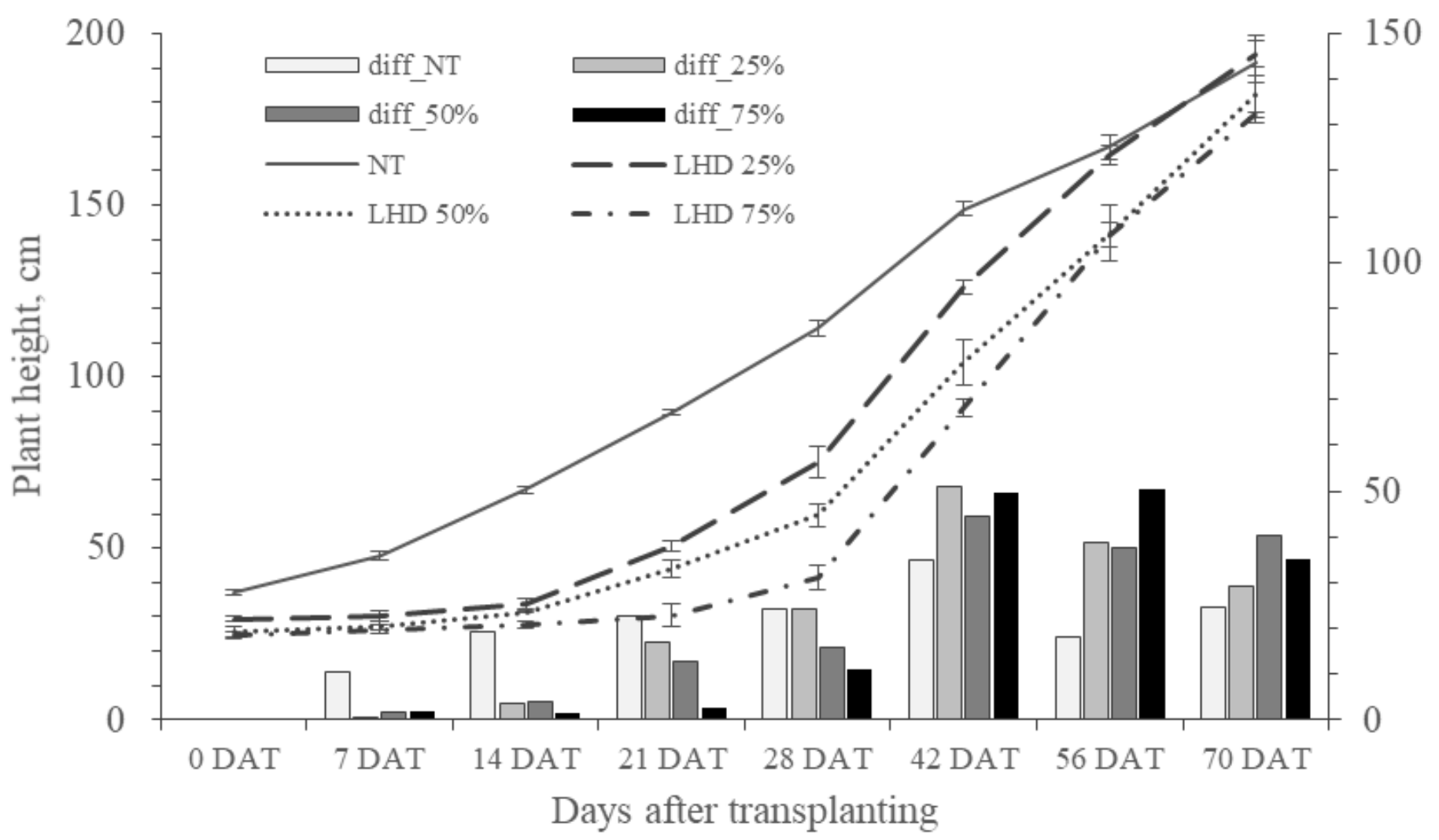

Figure 5

Effect of different leaf heat damage levels on plants growth rate in cv. "Chyung Yang" at recovery. Data represent the mean of 3 replications \pm SE. 


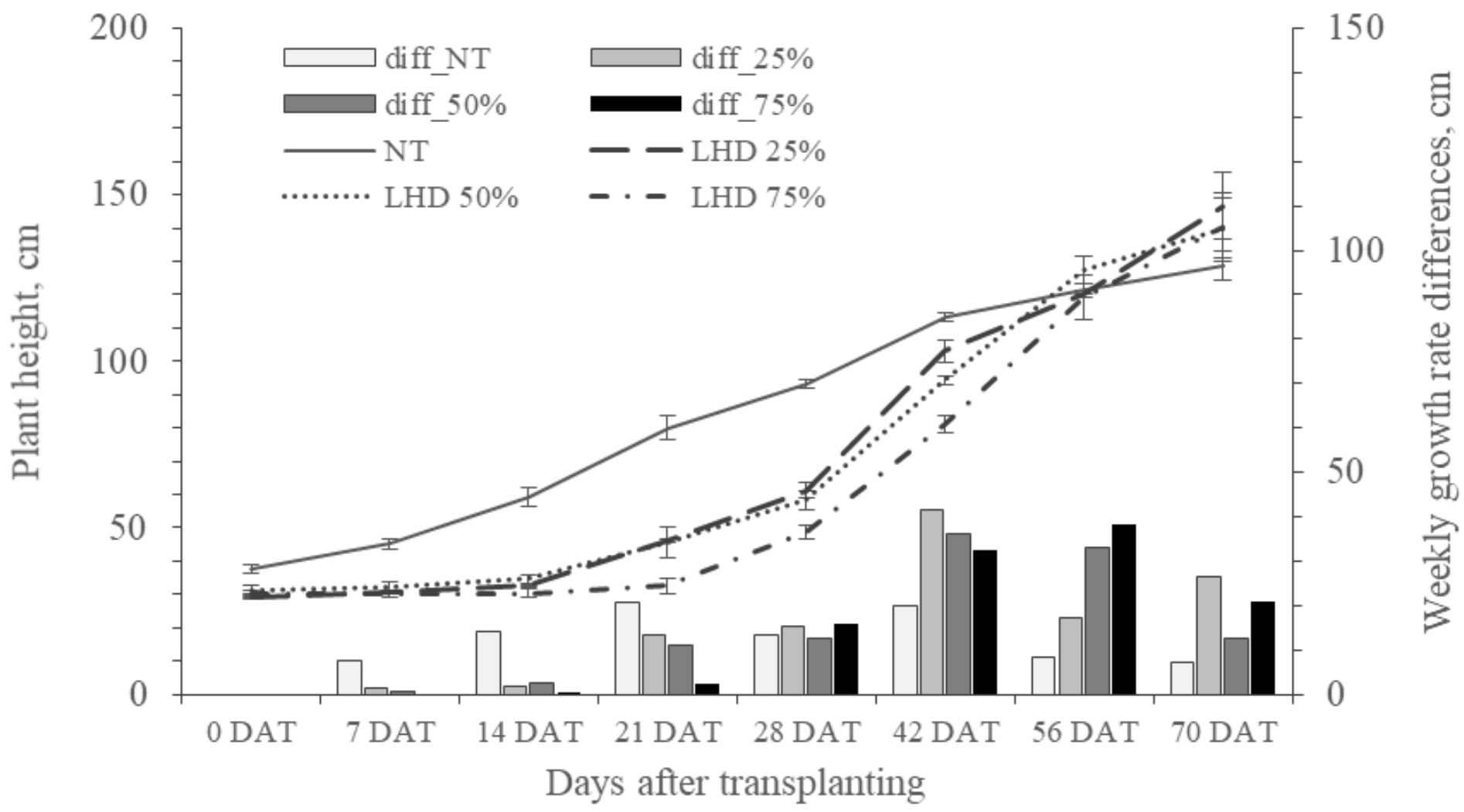

Figure 6

Effect of different leaf heat damage levels on plants growth rate in cv. "New Bigarim" at recovery. Data represent the mean of 3 replications \pm SE. 


\section{Cultivar "Chyung Yang"}

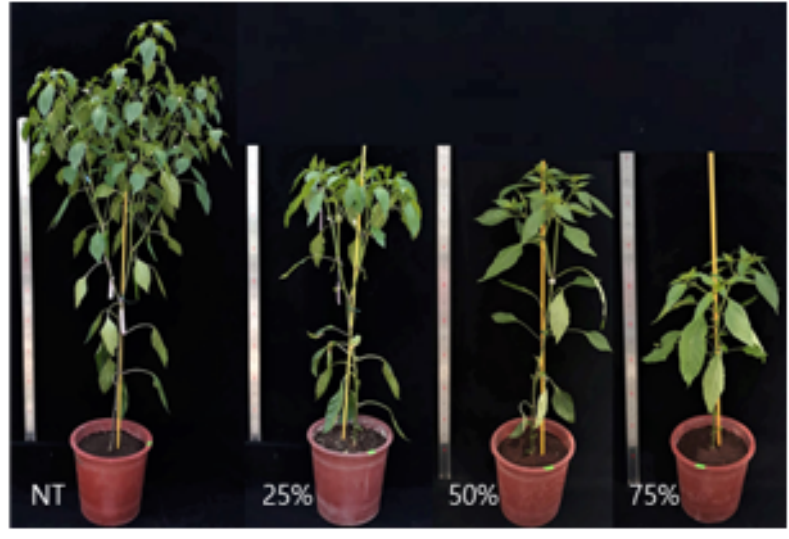

Plants after 30 days of transplanting

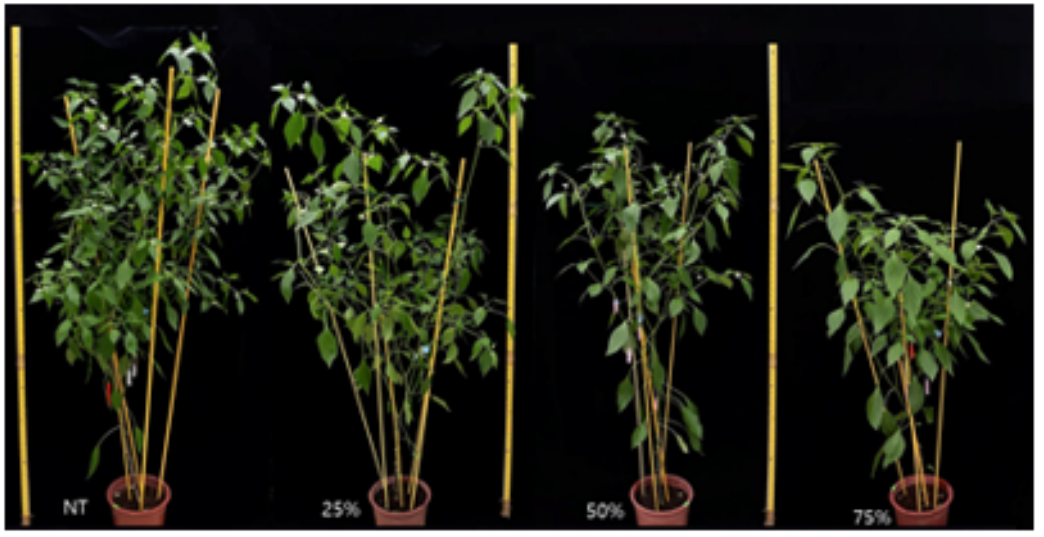

Plants after 55 days of transplanting

Cultivar "New Bigarim"

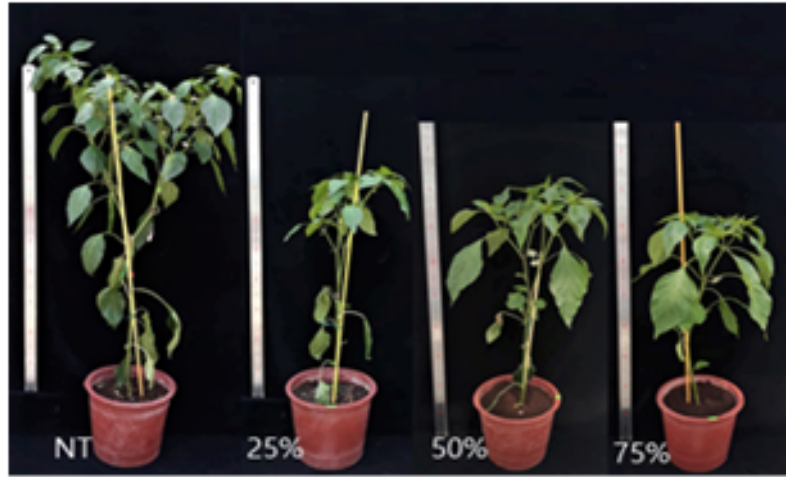

Plants after 30 days of transplanting
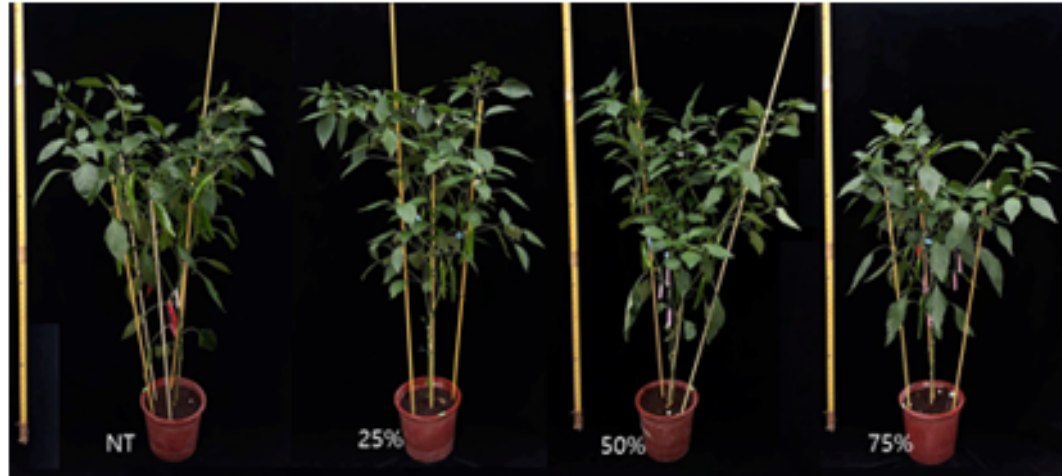

Plants after 55 days of transplanting

Figure 7

Recovery of pepper plants with different leaf heat damage levels

\section{Supplementary Files}

This is a list of supplementary files associated with this preprint. Click to download.

- SupplementarymaterialsRajametov.docx 